\title{
CARACTERIZAÇÃO FÍSICO-QUÍMICA DO SUBPRODUTO OBTIDO DURANTE A DESODORIZAÇÃO DO ÓLEO DE SOJA
}

\author{
GISELE M. BUCZENKO * \\ JUAREZ SOUZA DE OLIVEIRA ** \\ OSCAR FELIPPE VON MEIEN ***
}

\begin{abstract}
O presente trabalho teve por objetivo caracterizar física e quimicamente o destilado desodorizado de óleo de soja e verificar se esse subproduto é indicado para a recuperação de vitamina "E". O desodorizado foi analisado de acordo com as normas analíticas do Instituto Adolfo Lutz e métodos da Association of Official Analytical Chemists, sendo os tocoferóis determinados por cromatografia a gás. Foram encontradas $28,05 \%$ de matéria insaponificável, $73,65 \%$ de ácidos graxos, $7,41 \%$ de tocoferóis totais e $2,63 \%$ de $\alpha$-tocoferol. O destilado de óleo de soja mostrou-se adequado para a recuperação da vitamina "E".
\end{abstract}

PALAVRAS-CHAVE: DESODORIZAÇÃO; TOCOFERÓIS; ÓLEO DE SOJACARACTERIZAÇÃO.

\section{INTRODUÇÃO}

O óleo de soja, assim como outros óleos vegetais, para tornarem-se comestíveis devem sofrer processo de refino. A refinação química do óleo consiste em várias etapas que incluem basicamente a degomagem, a neutralização, o branqueamento e a desodorização (ALMEIDA et al., 1994).

A desodorização, última etapa no refino dos óleos comestíveis, exerce a função de remover sabores e odores indesejáveis (MORETTO e FETT, 1998). O processo de desodorização consiste em destilação por arraste de vapor em temperatura superior a $200^{\circ} \mathrm{C}$, com vácuo inferior a $10 \mathrm{~mm}$

* Mestranda em Tecnologia Química, Área de Concentração em Alimentos, Universidade Federal do Paraná (UFPR).

** Professor de Engenharia Química, Departamento de Engenharia Química, UFPR.

*** Professor de Engenharia Química, Curso de Pós-Graduação em Tecnologia Química, UFPR. 
de $\mathrm{Hg}$, durante 3 a 8 horas. Os parâmetros utilizados (temperatura, pressão e tempo) devem ser otimizados com a finalidade de produzir óleo comestível com características desejáveis e reconhecidas pelos consumidores. O subproduto obtido deste processo é denominado destilado desodorizado do óleo de soja (ALMEIDA et al., 1994; MAZA et al., 1992).

Pelo fato de existirem muitos tipos de óleos vegetais seria difícil listar todos os componentes desses óleos que produzem sabor e odor. Estes componentes, identificados em vários óleos, são as cetonas, aldeídos e ácidos graxos livres. Sua concentração é usualmente muito baixa, alcançando de $0,1 \%$ a $1,0 \%$. Experiências têm mostrado que a remoção de sabores e odores está relacionada com a redução de ácidos graxos livres do óleo. Se o óleo apresentar $0,1 \%$ de ácidos graxos livres seu odor será eliminado quando os ácidos graxos livres forem reduzidos para 0,01\% a 0,03\% (GAVIN, 1978).

O destilado desodorizado do óleo de soja (DDOS), obtido principalmente do processamento do óleo de soja bruto, é composto de ácidos graxos, esteróis, tocoferóis, ésteres de esteróis, hidrocarbonetos, produtos de ácidos graxos, aldeídos, cetonas e espécies de acilgliceróis. Destilados podem também conter grande quantidade de água e partículas estranhas (RAMAMURTHI e McCURDY, 1993; MARKS, 1988).

O desodorizado é a principal matéria-prima para a produção de vitamina "E" (FACIOLI e BARRERA, 2001). O destilado corresponde de $0,1 \%$ a $0,4 \%$ do peso original do óleo, e contém entre $0,8 \%$ a $10 \%$ de tocoferóis, sendo, portanto, fonte viável para a produção dos mesmos (ALMEIDA et al., 1994). Na Tabela 1 são apresentadas diferentes porcentagens de tocoferóis encontradas no DDOS.

Os tocoferóis pertencem à classe de antioxidantes lipossolúveis e estão presentes em todas as membranas celulares, lipoproteínas do plasma e células vermelhas do sangue. Sendo os antioxidantes lipossolúveis mais abundantes, os tocoferóis protegem o DNA das células e os ácidos graxos poliinsaturados da oxidação por radicais livres, motivo pelo qual são utilizados como antioxidantes naturais (SIQUEIRA et al., 1997). Esteróis são utilizados na manufatura de drogas farmacêuticas e, recentemente, têm sido empregados em alimentos funcionais (margarinas), pois apresentam a capacidade de inibir a absorção intestinal do LDL - colesterol associado ao processo de arteriosclerose (VERLEYEN et al., 2001). Ácidos graxos constituem de $25 \%$ a $75 \%$ do desodorizado dependendo 
do tipo do processo de refinamento empregado. O desodorizado pode apresentar diferentes características, usos e valores, sendo que o derivado do óleo de soja ou de outros óleos vegetais insaturados pode constituir adequada matéria-prima para a produção de vitamina "E" e esteróis. Os destilados de alguns óleos e gorduras podem ser úteis somente para produção de ácidos graxos, que apresentam poucas aplicações e são considerados de baixa qualidade em razão das etapas de processamento (RAMAMURTHI e McCURDY, 1993).

\section{TABELA 1 - PORCENTAGEM DE TOCOFERÓIS NO DDOS}

\begin{tabular}{lccc}
\hline COMPOSTOS & \multicolumn{3}{c}{ PORCENTAGEM (g/100 g de DDOS) } \\
\hline & RAMAMURTHI & CONTRERAS & ALMEIDA et al., 1994 \\
& e McCURDY, 1993 & e BARATA,1984 & \\
Tocoferóis totais & 12,7 & 8,7 & 3,5 \\
$\alpha$-tocoferol & 0,7 & 1,1 & 0,3 \\
$\beta$-tocoferol & 0,1 & 0,2 & n.d. \\
$\gamma$-tocoferol & 7,2 & 5,0 & 2,2 \\
$\delta$-tocoferol & 4,7 & 2,4 & 1,0 \\
\hline
\end{tabular}

n.d. = não detectado.

Existem duas razões para se determinar quantitativamente os tocoferóis no destilado desodorizado. Primeiro, o preço pago pelo destilado desodorizado depende do conteúdo de tocoferol (0,8\% a 10\%) e segundo, o conteúdo de tocoferol no destilado desodorizado é importante no monitoramento do rendimento e custos de manufatura (MARKS, 1988).

O DDOS é exportado como subproduto e retorna ao Brasil na forma de produto de alto valor comercial, os concentrados de vitamina "E", usados pela indústria farmacêutica, cosmética, alimentícia e de rações. O volume de DDOS gerado no Brasil permitiria a produção de vitamina "E" e seus derivados em quantidade suficiente para suprir a demanda interna (ALMEIDA et al., 1994).

O presente trabalho teve como objetivo caracterizar física e quimicamente o destilado desodorizado do óleo de soja e verificar se esse subproduto é indicado para a recuperação de vitamina "E". 


\section{MATERIAL E MÉTODOS}

\subsection{MATERIAL}

\subsubsection{Destilado desodorizado do óleo de soja (DDOS)}

A matéria-prima (DDOS) utilizada foi obtida na indústria de óleo de soja INCOPA, localizada no Município de Araucária, no Estado do Paraná, sendo que após a obtenção a amostra foi mantida sob refrigeração.

\subsection{MÉTODOS}

\subsubsection{Análises físico-químicas para a caracterização do DDOS}

A umidade foi determinada pelo método gravimétrico (IAL, 1985) e a densidade relativa em densímetro da marca INCOTERM, com escala de 0,900 a 1,000 .

A análise de cinzas foi realizada pelo método gravimétrico e o índice de refração pelo método físico de refratometria (IAL, 1985).

Determinou-se o índice de saponificação de acordo com as normas analíticas do Instituto Adolfo Lutz (1985).

Usou-se o método de neutralização por titulação (IAL, 1985) para determinar o índice de acidez e o método de Hanus (IAL, 1985) para determinar o índice de iodo.

As análises de matéria insaponificável foram efetuadas por gravimetria, segundo método 933.08 da AOAC (2000) e a de ácidos graxos totais pelo método 972.28 da AOAC (2000).

Os tocoferóis foram determinados por cromatografia a gas, utilizando-se o método modificado de NELSON et al. (1970). Empregou-se cromatógrafo a gás Hewlett-Packard (Modelo 5890 série II) com detector de ionização de chama (FID) e coluna de sílica fundida $(60 \mathrm{~m} \times 0,53 \mathrm{~mm}$ ) coberta com silicone (CP-Sil-5 CB, CHROMPACK). As condições cromatográficas, segundo o método 989.09 da AOAC (2000), foram a temperatura do forno $265^{\circ} \mathrm{C}$ (isoterma), o detector de ionização de chama $275^{\circ} \mathrm{C}$ e o injetor $275^{\circ} \mathrm{C}$. Nitrogênio ultrapuro foi usado como gás de arraste a pressão de $200 \mathrm{Kpa}$ e volumes de 1 a $2 \mu \mathrm{L}$ foram injetados no cromatógrafo. 


\section{RESULTADOS E DISCUSSÃO}

As principais características do destilado desodorizado do óleo de soja são mostradas na Tabela 2. Os valores representam as médias aritméticas das triplicatas com os seus respectivos desvios padrão.

\section{TABELA 2 - PRINCIPAIS CARACTERÍSTICAS FÍSICO-QUÍMICAS DO DDOS}

\begin{tabular}{l|l}
\hline CARACTERISTICAS & DDOS \\
\hline Umidade \% & $0,47 \pm 0,01$ \\
Matéria insaponificável \% & $28,05 \pm 0,79$ \\
Ácidos graxos totais \% & $73,65 \pm 0,12$ \\
Densidade relativa & $0,916 \pm 0,001$ \\
Índice de refração & 1,4710 \\
Índice de acidez & $35,40 \pm 0,31$ \\
Índice de saponificação & $130,20 \pm 1,08$ \\
Índice de iodo & $124,02 \pm 2,90$ \\
Cinzas \% & 0,04 \\
\hline
\end{tabular}

A umidade encontrada para o destilado desodorizado do óleo de soja mostrou-se acima dos valores citados na literatura. RAMAMURTHI e McCURDY (1993) determinaram a umidade de destilado desodorizado do óleo de canola e de desodorizado de soja e encontraram 0,02\% e 0,10\%, respectivamente. GHOSH e BHATTACHARYYA (1996) encontraram 0,15\% de umidade para o desodorizado do óleo de girassol.

O teor de matéria insaponificável é um dos fatores de grande importância nos métodos de purificação dos extratos para obtenção de rendimentos viáveis economicamente. Os componentes da matéria insaponificável são os tocoferóis, esteróis e hidrocarbonetos. GHOSH e BHATTACHARYYA (1996) determinaram a quantidade de material insaponificável em destilado desodorizado do óleo de girassol e encontraram $24,9 \%$, enquanto que o DDOS estudado por WOERFEL apresentou 38,7\%. ALMEIDA et al. (1994) analisaram o DDOS de três diferentes indústrias processadoras de óleo de soja localizadas no Estado de São Paulo e encontraram 27,1\%, 18,6\% e $3,5 \%$. As diferenças observadas na composição do DDOS ocorrem devido aos diversos sistemas empregados para a desodorização do óleo de soja e variações nos parâmetros dos processos. 
O destilado desodorizado do óleo de soja apresentou alto conteúdo de ácidos graxos totais, que não podem ser utilizados na alimentação humana (RAMAMURTHI e McCURDY, 1993).

A densidade relativa obtida nesse trabalho está de acordo com ALMEIDA et al. (1994), que encontraram valores de 0,916, 0,908 e 0,909 para três DDOS diferentes.

O índice de refração das gorduras eleva-se com o aumento do comprimento da cadeia de glicerídios e também com a insaturação e correlaciona-se com o índice de iodo que permite conhecer o grau de insaturação das moléculas. A determinação deste índice apresenta grande utilidade no controle dos processos de hidrogenação (MORETTO e FETT, 1998). As análises mostraram que o grau de insaturação do DDOS é semelhante ao dos óleos comestíveis.

O índice de acidez está intimamente relacionado com a qualidade da matéria-prima e o grau de pureza da gordura, com o processamento e, principalmente, com as condições de conservação da gordura (MORETTO e FETT, 1998). O valor obtido neste trabalho está de acordo com os encontrados na literatura, evidenciando bom estado de conservação do resíduo. ALMEIDA et al. (1994) obtiveram índice de acidez de 54,63; 40,67 e 34,10 para três DDOS diferentes e WOERFEL (1981) índice de 39,7 para destilado desodorizado do óleo de soja. Já RAMAMURTHI e McCURDY (1993) obtiveram índice de 44,8 e de 157,6 para destilado desodorizado do óleo de canola e GHOSH e BHATTACHARYYA (1996) encontraram índice de acidez de 28,8 para desodorizado de óleo de girassol.

Os ácidos graxos livres aumentam o índice de saponificação das gorduras vegetais, sendo que índice de saponificação elevado indica maiores possibilidades de aplicação para fins alimentares (MORETTO e FETT, 1998). ALMEIDA et al. (1994) encontraram diferentes índices de saponificação para três resíduos obtidos de indústrias processadoras de óleo (154,60; 145,10 e 173,60). GHOSH e BHATTACHARYYA (1996) analisaram o índice de saponificação de destilado desodorizado do óleo de girassol e obtiveram o valor de 138,1. Já o valor encontrado nesse trabalho evidencia que o subproduto analisado não é recomendado para fins alimentares.

O índice de iodo é a medida da insaturação da gordura, pois cada dupla ligação de um ácido graxo pode incorporar dois átomos de halogênio. Por 
essa razão, quanto maior a insaturação do ácido graxo maior será a sua capacidade de absorção de iodo e, conseqüentemente, maior será o índice (MORETTO e FETT, 1998). RAMAMURTHI e McCURDY (1993) analisaram o índice de iodo de destilados desodorizados de óleo de soja e de óleo de canola, obtendo os valores de 120,2 e 74,3, respectivamente. O valor encontrado nesse trabalho $(124,02)$ indicou a existência de quantidade pouco maior de ácidos graxos insaturados (ácido oléico, ácido linoléico e ácido linolênico) do que as citadas na literatura.

Na Figura 1 é apresentado o cromatograma dos acetatos de tocoferóis e esteróis e na Tabela 3 são listados os tempos de retenção dos mesmos.

\section{FIGURA 1 - CROMATOGRAMA DOS ACETATOS DE TOCOFERÓIS E ESTERÓIS}

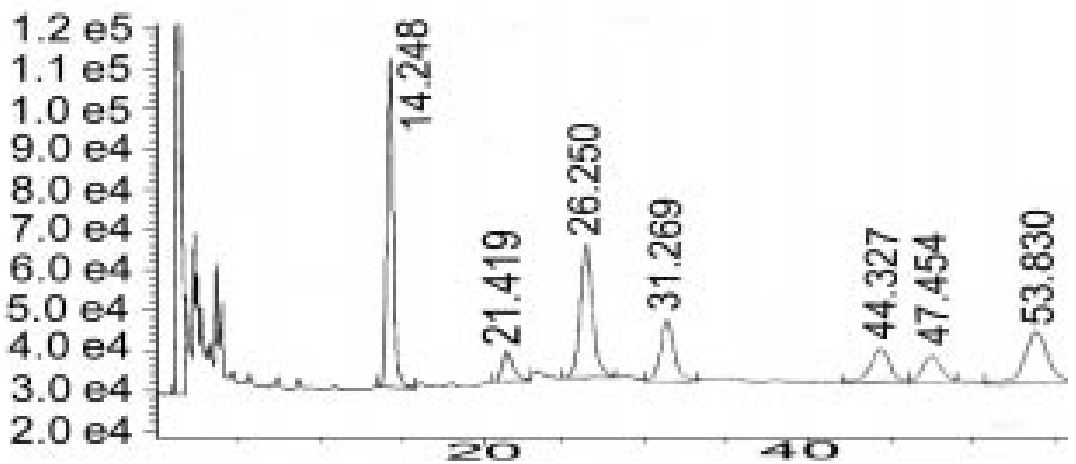

\section{TABELA 3 - TEMPO DE RETENÇÃO DOS ACETATOS DE TOCOFERÓIS E ESTERÓIS}

\begin{tabular}{l|c}
\hline COMPOSTOS & TEMPO DE RETENÇÃO (MINUTOS) \\
\hline Esqualeno & 14,248 \\
Acetato de $\delta$-tocoferol & 21,419 \\
Acetato de $\gamma$-tocoferol & 26,250 \\
Acetato de $\alpha$-tocoferol & 31,269 \\
Acetato de campesterol & 44,327 \\
Acetato de estigmasterol & 47,454 \\
Acetato de $\beta$-sitosterol & 53,830 \\
\hline
\end{tabular}


$\mathrm{Na}$ Tabela 4 são apresentadas as concentrações dos acetatos de tocoferóis. Os valores representam as médias aritméticas das triplicatas com os seus respectivos desvios padrão.

\section{TABELA 4 - ACETATOS DE TOCOFERÓIS}

TOCOFERÓIS

Total de acetatos de tocoferóis

Acetato de $\alpha$-tocoferol

Acetato de $\gamma$-tocoferol

Acetato de $\delta$-tocoferol
VALORES ENCONTRADOS

(g/100 g DO DDOS)

Conforme a Tabela 4 verificou-se que o isômero de tocoferol em maior concentração no DDOS estudado foi o acetato de $\gamma$-tocoferol com 3,74 g/ $100 \mathrm{~g}$ do DDOS. O acetato de $\beta$-tocoferol não foi detectado pelo método empregado devido provavelmente à pequena quantidade desse homólogo no DDOS. RAMAMURTHI e McCURDY (1993) analisando o DDOS verificaram que o $\gamma$-tocoferol foi o isômero que apresentou a maior concentração com 7,16 g/100 g do DDOS. O $\alpha$-tocoferol, o $\delta$-tocoferol e 0 $\beta$-tocoferol apresentavam 0,68 g/100 $\mathrm{g}$ do DDOS, 4,73 g/100 $\mathrm{g}$ do DDOS e $0,18 \mathrm{~g} / 100 \mathrm{~g}$ do DDOS, respectivamente. ALMEIDA et al. (1994) analisaram diferentes DDOS e determinaram os tocoferóis por cromatografia a líquido. Encontraram para um DDOS 2,20 g/100 g do DDOS de $\gamma$-tocoferol, $0,30 \mathrm{~g} / 100 \mathrm{~g}$ do DDOS de $\alpha$-tocoferol e $1,00 \mathrm{~g} / 100 \mathrm{~g}$ do DDOS de $\delta$-tocoferol. Em todas as análises o $\beta$-tocoferol não foi detectado, pois encontrava-se abaixo do limite de sensibilidade do método. Os valores encontrados para $\gamma$-tocoferol mostraram-se semelhantes aos citados na literatura, já as variações nas concentrações dos demais isômeros podem ocorrer porque as condições do processo de refino do óleo não são as mesmas para todas as indústrias.

\section{CONCLUSÃO}

O destilado desodorizado estudado é indicado para a recuperação de vitamina "E", pois apresentou concentração razoável de tocoferóis totais $(7,41 \mathrm{~g} / 100 \mathrm{~g}$ do DDOS) e $(2,63 \mathrm{~g} / 100 \mathrm{~g}$ do DDOS) do isômero $\alpha$, o qual apresenta a maior atividade vitamínica. Os ácidos graxos são compostos que aparecem em alta concentração no DDOS, mas por apresentarem baixa qualidade não podem ser utilizados na alimentação. 


\begin{abstract}
PHYSICO-CHEMICAL CHARACTERIZATION OF THE BY-PRODUCT OBTAINED DURING THE DEODORIZATION OF SOYBEAN OIL

The aim of the present work was to characterize physical and chemically the deodorized distillate from soybean oil and verify if the deodorizer is suitable for vitamin "E" recovery. The deodorizer was analyzed in agreement with the Analytic Norms of the Instituto Adolfo Lutz and AOAC methods being the tocopherols determined by gas chromatography. It was found $(\mathrm{w} / \mathrm{w})$ : unsaponifiable matter - $28,05 \%$, fatty - $73,65 \%$, total tocopherols $7,41 \%$ and $\alpha$-tocopherol $-2,63 \%$. The distillate from soybean oil is suitable for vitamin "E" recovery.
\end{abstract}

KEY WORDS: DEODORIZATION; TOCOPHEROLS; SOYBEAN OILCHARACTERIZATION.

\title{
REFERÊNCIAS
}

1 ALMEIDA, M. E. M.; GUSMAN, E. C.; CARVALHO, P. R. N.; RUSIG, O. Avaliação de destilado da desodorização do óleo de soja para a extração de vitamina E. Arquivos de Biologia e Tecnologia, v. 37, n. 4, p. 1003-1011, 1994.

2 AOAC. Association of Official Analytical Chemists. Official methods of analysis of AOAC international. $17^{\text {th }}$ ed. Arlington, 2000.

3 CONTRERAS, E.; BARATA, L.S. Recuperação da vitamina E dos resíduos da indústria de óleos vegetais. Campinas: FUNCAMP, 1984. 23 p. Relatório técnico.

4 FACIOLI, N. L.; BARRERA, A. D. Optimization of enzymatic sterification of soybean oil deodorizer distillate. Journal of the Science of Food and Agriculture, v. 81, n. 12, p. 1193-1198, 2001.

5 GAVIN, A.M. Edible oil deodorization. Journal of the American Oil Chemists' Society, v. 55, p. 783-791, 1978.

$6 \mathrm{GHOSH}, \mathrm{S}$.; BHATTACHARYYA, D. K. Isolation of tocopherol and sterol concentrate from sunflower oil deodorizer distillate. Journal of the American Oil Chemists' Society, v. 73, n. 10, p. 12711274, 1996.

7 IAL. INSTITUTO ADOLFO LUTZ. Normas Analíticas do Instituto Adolfo Lutz. São Paulo, 1985. 523 p. 
8 MARKS, C. Determination of free tocopherols in deodorizer distillate by capillary gas chromatography. Journal of the American Oil Chemists' Society, v. 65, n. 12, p. 1936-1939, 1988.

9 MAZA, A.; ORMSBEE, R. A.; STRECKER, L.R. Effects of deodorization and steam-refining parameters on finished oil quality. Journal of the American Oil Chemists' Society, v. 69, p. 10031008, 1992.

10 MORETTO, E.; FETT, R. Tecnologia de óleos e gorduras vegetais na indústria de alimentos. São Paulo: Varela, 1998.

11 NELSON, J. P.; MILUN, A. J.; FISHER, H. D. Gas chromatographic of tocopherols and sterols in soy sludges and residues - an improved method. Journal of the American Oil Chemists' Society, v. 47, p. 259-261, 1970.

12 RAMAMURTHI, S.; McCURDY, A. R. Enzymatic pretreatment of deodorizer distillate for concentration of sterols and tocopherols. Journal of the American Oil Chemists' Society, v. 70, n. 3, p. 287-295, 1993.

13 SIQUEIRA, F. M.; OETTERER, M.; REGITANO-D'ARCE, M. A. B. Nutrientes antioxidantes. Boletim da Sociedade Brasileira de Ciência e Tecnologia de Alimentos, v. 31, n. 2, p. 192-199, 1997.

14 VERLEYEN, T.; VERHE, R.; GARCIA, L.; DEWETTINCK, K.; HUYGHEBAERT, A.; GREYT, W. Gas chromatographic characterization of vegetable oil deodorization distillate. Journal of Chromatography, v. 921, p. 277-285, 2001.

15 WOERFEL, J. B. Processing and utilization of by-products from soy oil processing. Journal of the American Oil Chemists' Society, v. 58 , p. 188-191, 1981. 